\title{
Teacher's Actions to Promote Flexibility in Mental Arithmetic
}

\author{
Lurdes Serrazina \\ Margarida Rodrigues \\ Escola Superior de Educação, Instituto Politécnico de Lisboa, \\ UIDEF, Instituto de Educação, Universidade de Lisboa
}

In this article, we discuss teachers' actions to develop flexibility in students' mental arithmetic. We analyze the actions of a second-grade teacher during the whole-class discussion of a task, included in a sequence of tasks designed to promote calculation flexibility. Flexibility is a competence that students should develop at school, and teachers' actions are crucial for fostering flexible mental calculation by which students establish number relations. Data were collected through observation by the authors along with videotaping the activity and transcribing recorded speech. In data analysis, we examined how the teachers' actions and questions were critical for students to focus on the properties of numbers and operations and thereby improve their calculation flexibility. The teacher's supporting/guiding and challenging actions were most frequently used during the whole class discussion, and they showed a greater influence in developing a conceptual understanding underlying the calculation flexibility. These specific actions, in conjunction with other actions, such as inviting and informing actions, appear fundamental in leading students forward in establishing number relationships.

Keywords: teachers' actions, flexibility in mental arithmetic, conceptual understanding, number relations

This article is part of a project which aims to characterize the development of students' numerical thinking and flexibility in mental calculation from 6 to 12 years and to describe teachers' practices that facilitate that development. Calculation strategies can be used by students in a mechanized way, regardless of the context of the task or the numbers involved (Brocardo, 2014), and in this sense, students can show mastery of procedural skills without understanding the underlying mathematics. Hence, the ability to properly apply the knowledge that has been acquired in another situation to a new one is fundamental to the development of mathematical proficiency (NCTM, 2000). For Threlfall (2009), students use a flexible mental calculation when they meet the contextual variables of a given task or specific numbers, and establish relationships with their previous numerical knowledge.

How teachers promote and organize classroom discussions and the kind of questioning may be an important role in the development of students' flexible 
mental calculation with a focus on conceptual understanding. The goal of this article is to extend our understanding of how teachers' actions during the whole-class discussion promote students' flexibility in mental addition. This article focuses on one task integrated into a sequence of tasks and analyzes the influence of the teacher's actions to encourage students' participation in discussion and establish number relations in additive problems. The study reported here was aimed at answering the following empirical questions: What are the teacher's actions during the whole class discussion? To what extent are the teacher's actions related to students' flexibility in mental arithmetic?

\section{Theoretical Framework}

\section{Flexibility in Mental Arithmetic}

The idea of calculation flexibility is related to mental arithmetic problems which can be resolved in different ways, usually called strategies. A flexible calculation has been considered an ability that all students should develop in elementary school (Anghileri, 2001), and its relevance has been recognized in mathematics education. Being proficient in mathematics implies the ability to compute efficiently, accurately, flexibly, and appropriately (Kilpatrick et al., 2001).

The literature reveals little consensus regarding the meaning of "flexibility." Some authors (e.g., Star \& Newton, 2009) consider flexibility as "students' knowledge of multiple strategies and their ability to select the most appropriate strategy for a given problem" (p. 578). Verschaffel et al. (2009), from a literature review, use the dual term 'flexibility/adaptivity': 'flexibility' "for the use of multiple strategies and 'adaptivity' for making appropriate strategy choices" (p. 338). Based on Hatano's (2003) definition of adaptive expertise - "the ability to apply meaningful learned procedures flexibly and creatively" (p.xi), Selter (2009) considered that "creativity and flexibility are requirements of adaptivity" (p. 620). Finally, Torbeyns et al. (2009) presented two definitions of strategic flexibility. One is the choice between different strategies only based on the characteristics of the task. Another is considered a more sophisticated definition "wherein strategic flexibility is conceived as selecting the strategy that brings the child most quickly to an accurate answer of the problem" (p. 583).

Trying to overcome the problems inherent in this discussion about the meaning of flexibility in mental calculation, Rathgeb-Schnierer and Green (2013) presented a definition as a way of acting. However, for them, the meaning of flexibility is not related to a choice of the best strategy nor with the fastest way to get a solution, rather, it is "the recognized number patterns and relationships of a given problem in the context of processing a problem solution" (p. 357). This implies students' knowledge about numbers and operations that enables them to recognize the characteristics of the problem, namely, numerical patterns and relations between numbers. So, this definition 
"reflects an attention to both solution methods as well as number patterns and relationships embedded in problem structures" (Rathgeb-Schnierer \& Green, 2019, p. 8).

The study reported here takes the perspective of Threlfall (2009) as well as Rathgeb-Schnierer and Green (2013), considering strategic flexibility as the way an arithmetic problem is affected by circumstances to be mentally solved. These circumstances may be related to specific features of the tasks or contextual variables or personal characteristics. Threlfall (2009) argues that in a flexible calculation, "the calculation-strategy is not selected and applied, it is arrived to" (p. 548). For him, the emergence of strategies occurs through a process named zeroing-in, which is a not fully conscious mechanism, involving partial exploratory calculations arising from noticing specific features of the numbers involved and their respective relationships. This perspective diverges from several authors (Heinze et al., 2009; Heirdsfield \& Cooper, 2004; Star \& Newton, 2009) who define flexibility as knowing multiple solution pathways as well as the capacity to choose the most appropriate for a given problem. Like Threlfall (2009) and Rathgeb-Schnierer and Green (2013), Baroody and Rosu (2006) rejected this strategy-choice model, referring to flexibility in calculation as related to the fact that children discover number patterns, as they develop number sense, thereby building a network of numerical relationships. Rechtsteiner-Merz and Rathgeb-Schnierer (2015) introduce the term 'Zahlenblick' as 'the competence to recognize problem characteristics, number patterns, and numerical relationships immediately, and to use them for solving a problem" (p. 355). For these authors, the approach of 'Zahlenblickschulung' is an important vehicle to develop a flexible mental calculation.

According to Baroody and Rosu (2006), what matters is the ability to produce new known facts from old ones, acting as an autonomous meaningful knowledge generator instead of the ability to efficiently produce meaningless answers from a memory network. Gray and Tall (1994) distinguish known facts from deduced facts, and they argue that known facts do not necessarily lead to the deduction of new facts, which depends on the flexibility to use known facts. One example of such flexibility can be found in arithmetic doubles, which we highlight in the study reported here. For example, starting with the double of $25: 25+25(50)$ - then 51 is a near double $(50+1$ or $25+$ $25+1$ ); or in reverse, $51-25=26$, because $26=25+1$ and 25 is half of 50 . Thus, the double/half relation can be used to deduce new facts.

Developing flexible calculation strategies involves developing networks of numerical relationships in which numbers become objects of thought (Gravemeijer \& Bruin-Muurling, 2019; Gravemeijer et al., 2016). As reasoned by Gravemeijer and Bruin-Muurling (2019, p. 18), "numbers as objects allow for flexibly using number relations to solve tasks in the domain of number." Students can think about additions and subtractions in a relational way in order to form coherent sets of number relations (for instance, $34+20=$ 
$54,20+34=54,54-20=34$ and $54-34=20$ ). In this way, sums and differences become mathematical objects with which students can act and reason. This contrasts to numbers as cogs in a series of algorithmic steps. Numbers must be structured by students so that they are composed and recomposed in a wide variety of ways that, when combined, constitute a rich conceptual structure (Gray \& Tall, 1994). "Numbers, sums, and differences have to become mental objects that can be composed and decomposed in different ways, which in turn forms the basis for flexible arithmetic and an expansion to bigger numbers, and later for integers and algebra" (Gravemeijer et al., 2016, p. 37). As argued by Gravemeijer and Bruin-Muurling (2019), the flexible use of number relations may enhance a deeper understanding of the operations involved.

\section{Teachers' Actions}

How teachers question students during the whole-class discussion is a fundamental aspect of classroom communication (Boaler, 2003; Ponte \& Quaresma, 2016). Different points of view should be considered, and students should be encouraged to explain and justify their reasoning and solutions, thus developing, with the teachers' support, their understanding (Ruthven et al., 2011). One important challenge is that the ideas students develop are aligned with the mathematical concepts and procedures that we want them to know. In any case, they should be able to establish numerical relationships by thinking of numbers as mental objects. For that, teachers should plan lessons that include questions that support and extend students' thinking. So, a fruitful whole class discussion requires a strong commitment from the teacher, beginning with lesson planning, anticipating student resolutions, thinking about which questions should be made, and supporting students when they work in pairs trying to solve the task. In that context, teachers need to identify student works to be discussed and in which order, and culminate with wholeclass discussion, where a teacher's actions are decisive. For analyzing a discussion, Ponte et al. (2013) distinguished four different teachers' actions related to mathematical aspects: (a) Inviting, seeking to initiate a discussion; (b) Supporting/Guiding to lead students to present information or to focus on a specific mathematical idea, making questions or observations; (c) Informing/Suggesting, introducing information, giving suggestions, validating students' responses; and (d) Challenging to encourage students to produce new representations, interpret a statement, establish connections, or formulate reasoning or an evaluation.

With regard to arithmetic teaching, teachers should support students to expand the variety of number relations and to transcend the "splitting /jumping dichotomy" (Gravemeijer \& Bruin-Muurling, 2019, p. 26) - this dichotomy refers to the two mechanized procedures of calculating, either by splitting or jumping. For these authors, it is important that, under the guidance of the teacher, students reason with number relations when they solve 
problems of addition and subtraction; that is, "they will come to think of adding and subtracting as composing and decomposing mathematical objects" (p. 26) in contrast to traditional memorization that emphasizes speed and accuracy over meaning. For example, tasks such as $85-49$, might be solved by comparing it with 85-50, which is easier and then, 85-50=35 and 85-49=36. According to the authors, from this task, the teacher can also work other relations with students, such as $85-36=49$ and $49+36=85$. So, the teacher must be able to maintain the cognitive demands of the task, fostering "the transition from jumping and splitting as procedures to construing sums and differences as objects" (Gravemeijer \& Bruin-Muurling, 2019, p. 22), focusing students' work on the goal of understanding the underlying mathematics and not so much on mastery of procedural skills.

\section{Methodology}

Our study focused on examining the teacher's actions during a planned whole-class discussion of a task designed to foster flexibility in mental arithmetic. That strategy provided data about both cognitive flexibility and teacher actions summarized above.

This study follows a qualitative approach framed in an interpretative paradigm (Bogdan \& Biklen, 1994). It is focused on the educational processes and the meanings of the study participants (Erickson, 1986). The study is part of a large project whose main goal is mentioned before. The project adopts the modality of design research conceived to produce local teaching theories and teaching sequences that can contribute to informing teachers' practices (Gravemeijer \& Cobb, 2006). In particular, these local teaching theories will involve teaching practices that promote flexibility in mental arithmetic.

This article focuses on the whole class discussion of the task "Cards with numbers" fulfilled in October 2015, in the 2nd grade with 26 students, and whose goal is to use known facts to establish number relations and to calculate flexibly. The task was the 3rd of a sequence of 6 tasks which were previously discussed with the teacher and adapted by her. This teacher was a primary teacher with more than 10 years of teaching experience and who had active participation in projects and in-service education courses related to mathematics education; she was selected for her availability to collaborate with our project. For the task, 18 cards shown in Figure 1 were distributed to the students. The cards included number values the teacher believed her students knew as number facts as well as expressions with numbers close to the previous ones so that the students could deduce them by relating them to the known facts.

Then, each student received a sheet to record the expressions on the cards, separating them into two columns: those that students knew quickly and those that students did not know quickly. A similar task was used in RathgebSchnierer and Green (2015) where the students were asked to sort 12 two-digit 
addition and subtraction expressions displayed on cards as either 'easy' or 'hard' and to explain their sorting.

\begin{tabular}{|c|c|c|c|c|}
\hline $11+25$ & & $19+25$ & & $100-52$ \\
\hline & $50-25$ & & $25+21$ & \\
\hline $25+25$ & & $50-30$ & & $100-48$ \\
\hline & $50-21$ & & $52-30$ & \\
\hline $25+9$ & & $50-20$ & & $100-50$ \\
\hline $50-29$ & $20+25$ & $25+26$ & $52-29$ & $10+25$ \\
\hline
\end{tabular}

Figure 1. Cards Distributed to Students.

The teacher introduced the task and answered students' questions about the task. Then students began to solve the cards in teacher-assigned pairs. During that time the teacher observed the work of her students and answered some occasional doubts. When all the pairs had solved the task (with all 18 problems completed), the teacher put all the cards on the blackboard and started the whole class discussion asking one pair to go to the blackboard. The discussion began by focusing on one of the pair's most difficult cards. The discussion reported here lasted 30 minutes.

Table 1

Analytical Categories of Teacher's Actions

\begin{tabular}{ll}
\hline Categories & Actions \\
\hline Inviting & Requests reports as they did \\
& Requests answers for specific questions \\
Supporting/Guiding & Provides clues to students \\
& Encourages explanation \\
& Focuses student's thinking \\
& Encourages students to re-say \\
& Encourages students to elaborate in their \\
& answers \\
Informing/Suggesting & Gives information and explanations \\
& Validates responses provided by students \\
& Corrects student-provided answers \\
& Reworks answers provided by students \\
Challenging & Requests explanations and justifications from \\
& students \\
& Encourages student reflection \\
& Presses for accuracy \\
\hline
\end{tabular}


The observation data collection was done by the authors of this article, complemented with field notes and videotaping of the lessons. The names of the students have been changed to ensure confidentiality. The analysis focused on field notes, video recordings, and transcriptions. The analytic categories shown in Table 1 are the teachers' actions related to the whole-class discussion, as considered by Ponte et al. (2013).

These categories were used because they are closely linked to wholeclass discussion management and are also suitable to analyze discussions focused on fostering flexibility in mental arithmetic. The data were coded separately by the two authors of this article and then put together. The level of agreement was $90 \%$. The situations with disagreement were discussed and consensually agreed upon.

\section{Results}

Results are reported sequentially for selected pairs of students. Adequate excerpts from the whole-class discussion are incorporated where the teacher's actions are more visible.

With all the cards posted on the board, the teacher invited the pair Mónica and Gil to go to the blackboard and choose the most difficult card for them (Code: Inviting Action). Gil picked up the card 100-48 as being the most difficult and put it to the side on the board.

Teacher-Let's see if we can help. Which is the card similar to it that may help? (Code: Guiding Action)

Gil picked up the card 100-50 and put it below 100-48. Mónica picked up 10052 putting it below.

Teacher: Why that one (referring to 100-52) also may help? (Code:

Challenging Action)

Gil and Mónica stayed near the board. The teacher asked Maria and Gabriel to go to the blackboard to present their justifications related to the cards selected by Gil and Mónica.

Maria: Because 52 is an even number.

(...)

Gabriel: This [100-50] helps more than this [100-52].

Teacher: Why? (Code: Challenging Action)

Gabriel: Because this [50] is half of this [100].

Teacher: Because 50 is half of 100. How much is 100-50, Mónica? (Code:

Guiding Action)

Renato (talking sitting in his place): 50 is in the middle before 50 is 49 and

then 48 after 50 is 51 and after 52.

Gabriel: This [100] minus 50 will give 50.

Teacher: [pointing to the card 100-50] How can this help to make 100 minus 48? Let's think. (Code: Guiding Action)

The teacher wrote " $=50 "$ on the board, as shown in Figure 2. 


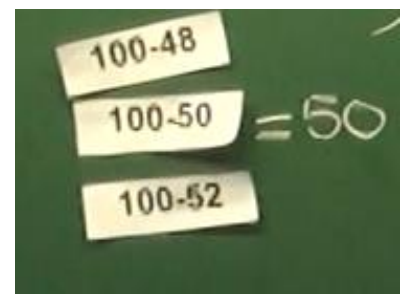

Figure 2. 100-50 Aiding to Determine 100-52 and 100-4.

With her actions, the teacher invited Mónica and Gil to present a difficult card and then guided and challenged them through her questioning. Other students tried to justify the relations between the cards. Maria did not know the answer but decided to point out the fact that 52 is an even number. Gabriel used the double/half relation to get 100-50. Then the teacher guided him to relate this number fact to deduce 100-48. She asked the students to sit down, and the discussion continued.

Teacher: Gil, you chose 100-50 and after you also picked up 100-52, why? (Code: Challenging Action)

Ilda raised her hand and the teacher asked her to go to the board.

Ilda: 52 is plus 2 than 50.50 minus 2 is 48 .

Teacher: How much is 100-52 and 100-48? You still haven't answered.

The teacher asked Renato and Dario to go to the board.

Gabriel (talking sitting in his place): 100 minus 52 is 48 .

Teacher: How do you know? (Code: Challenging Action)

Gabriel (went to the board): Because if 100 minus 50 is 50, then it takes out 2 more and will give 48.

Teacher: It takes out 2, where? (Code: Guiding Action)

Gabriel: [pointing to the result of 100-50 written by the teacher] At 50. (The teacher writes $=48$ in front of the card 100-52).

The teacher asked again why Gil and Mónica had chosen the card 100-52, looking to have a justification, challenging them. Other students contributed to the discussion. Ilda seemed to relate 50 with both 52 and 48 . Gabriel seemed to have understood the property of compensation, and he was able to apply it appropriately.

Renato: Here is 52 [looking for 100-48].

Teacher: Why? (Code: Challenging Action)

Renato: Because 100 minus 50 will give 50. And as 48 is minus 2, it will give 52 [the teacher wrote " $=52$ " on the board].

Renato showed some facility with calculation. Analyzing the sequence of interactions, we infer the teacher's actions sought to keep students focused on establishing number relations to deduce new facts from known ones and 
thereby advance their thinking. The teacher continued guiding the students by questioning:

Teacher: So, these two expressions, what are they in relation to each other? [pointing to the expressions: $100-48=52$ and 100-52=48]. (Code: Guiding Action)

Armando raised his hand, and the teacher asked him to go to the board.

Armando: [pointing to 48 in both expressions and then to 52]: This [48, in the first expression] is the result of this [pointing to the second expression], and this [52 in the second expression] is this [the result of the first expression].

Teacher: What does it mean? (Code: Challenging Action)

[All the students were in a prolonged silence].

The teacher tried to guide the students to relate the expressions recorded on cards $(100-48 ; 100-52)$ by challenging them to interpret the situation. As the students remained silent, the teacher rephrased what Armando had said:

Teacher: This 52 appears as the result of 100-48=52, and this 48 appears as the result of 100-52=48. Why does this happen? (Code: Challenging Action).

The teacher asked again for a justification from the students, but they continued in silence. She did not give up and continued challenging them to obtain a justification for the situation. From the conversations we had before with this teacher, we infer that for her it was important to lead students to go beyond the calculations and understand what happened beyond the concrete numbers. So, she decided to overcome the situation by asking them to present another similar example:

Teacher: So, give me another example where this also happens (...) One other example where the numbers also appear exchanged? (Code: Supporting Action)

Gabriel went to the board and wrote $100-51=47$, but quickly rectified:

Gabriel: Gives 49.

Paulo (talking sitting in his place): 100-49=51 [Gabriel's board work is shown in Figure 3]

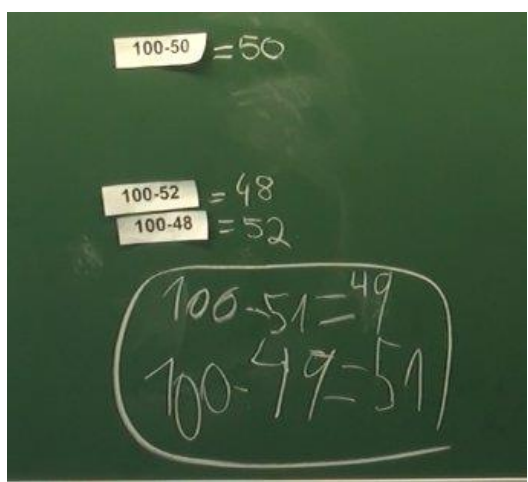

Figure 3. Gabriel's Example Illustrative of the Part-whole Relation. 
The teacher supported the students' efforts to achieve the part-whole relation by suggesting they find a new example. Then she continued pressing them to justify the exemplified relationship:

Teacher: Why does it happen? So, why can you change? (Code: Challenging Action)

Luís [goes to the board and points to the numbers when he verbalizes them] Because 49 plus 51 gives 100, and 51 plus 49 gives 100. [points to the cards above] 48 plus 52 gives 100. And 52 plus 48 gives 100 .

Teacher [goes to the board and points to the numbers]: If I take 52, I get 48. If I do the opposite, from 100 take 48, it has to stay with... (Code: Informing Action)

Students (in chorus): 52.

Teacher: 52. 52 plus 48 has to give 100. 48 plus 52 has to give 100. That's what happens here in this example too that you gave. (Code: Informing Action)

Luís: This happens always.

With the teacher's challenging action, Luís seems to have understood that sums and differences become numbers, and he appears to work with them as both mental objects and number relations. Luis understood the relationship between addition and subtraction and the relations between different numbers in both operations. When the teacher went to the board and rephrased what Luís had said, she tried to ensure that all the students understood the situation. Probably, Luís's generalization derives from understanding number relations as well as the inverse between addition and subtraction.

After that, the teacher invited another pair to go to the blackboard to write the most difficult expression for them (Code: Inviting Action). The pair João and Paulo went to the blackboard and chose the cards 52-29 and 50-29 as being difficult, relating them to 50-30.

Teacher: How much is 50 minus 30? (Code: Guiding Action)

Paulo: It is 20 [writes on the board in front of the card]

Teacher: How much is 50-29? [Paulo records 19 on the board on the front of the card] 19? [The teacher approaches the board] 50 minus 30 is 20. Here takes out minus 1 [points to 29] must stay there [Paulo corrects to 21]. (Code: Supporting Action)

Teacher: What's going on from here [points to 50 in the card 50-29] to here [points to 52]? (Code: Guiding Action)

Paulo: It is plus 2.

Teacher: In a subtraction, we have already seen that if we want to keep the result, what I do in the additive, I have to do it in the subtractive [points to the respective numbers] (Informing action). If I'm just doing it in the additive, the result will change. If I'm putting 2 more, what will happen here [points to the place in front of the equal sign in 52-29]? (Code: Guiding Action). 
Paulo: Is it plus 2 or minus 2?

Teacher: Good question. You already know that when I increase 1 to the additive, I have to increase 1 to the subtractive. From here to here [points to cards 50-29 and 52-29] I'm not changing the subtractive, I'm changing here [points to the additive in both cards]. I do plus 2. But here [points to the subtractive in the two cards] I don't do plus 2. What does happen in the answer? It will change. (Code: Guiding Action)

Student: It is 23. [Paulo records 23]

Teacher (comparing 52-29 and 50-29): If I am putting plus 2 here [points to 52], I am removing the same [points to 29], I have 2 more, it is what he is saying... [refers to the student who said 23 whose name is inaudible]. (Code: Informing Action)

Figure 4 shows the records done by Paulo.

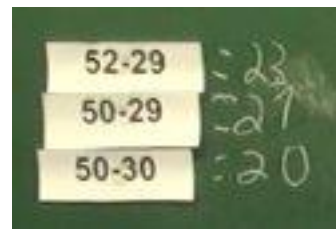

Figure 4. Paulo Figuring out 52-29.

With actions of guiding, supporting, and informing, the teacher tried to help the students understand the relations between different numbers and the subtraction proprieties. She used the informing action to help students remember the property of invariance, and she used the guiding action to lead students to understand the compensation resulting from changing the additive (which troubled Paulo).

Continuing the whole class discussion, the teacher knew that Nadia and Santiago had used the empty number line to solve the same problems (100-52 and 100-48; 52-29 and 50-29), so she invited:

Teacher: Someone did it differently? (Code: Inviting Action)

Nadia and Santiago went to the blackboard and drew their scheme on the board, for $100-52$ and $100-48$.

Teacher: So, explain! (Code: Inviting Action)

Nadia: To do the 48 [points to 48 in the number line] we use the 100-50 that gave 50 .

Santiago: And then we went to 100 again, we took 52 that gave 48.

Teacher: You took two more. It gave 48. (Code: Informing Action)

Then the pair drew their scheme relative to 52-29 and 50-29, shown in Figure 5.

Nadia and Santiago: From 52, we took 22; it gave 30. We went to 52 again, and we took 23; it gave 29.

Teacher: Why does 52-23 help to calculate 52-29? There is no 52-23. (Code: Challenging Action) 
Nadia: 29 is before 30.

Teacher: [points to 23 written in front of the card 52-29] But here is 23, not $29 .$.

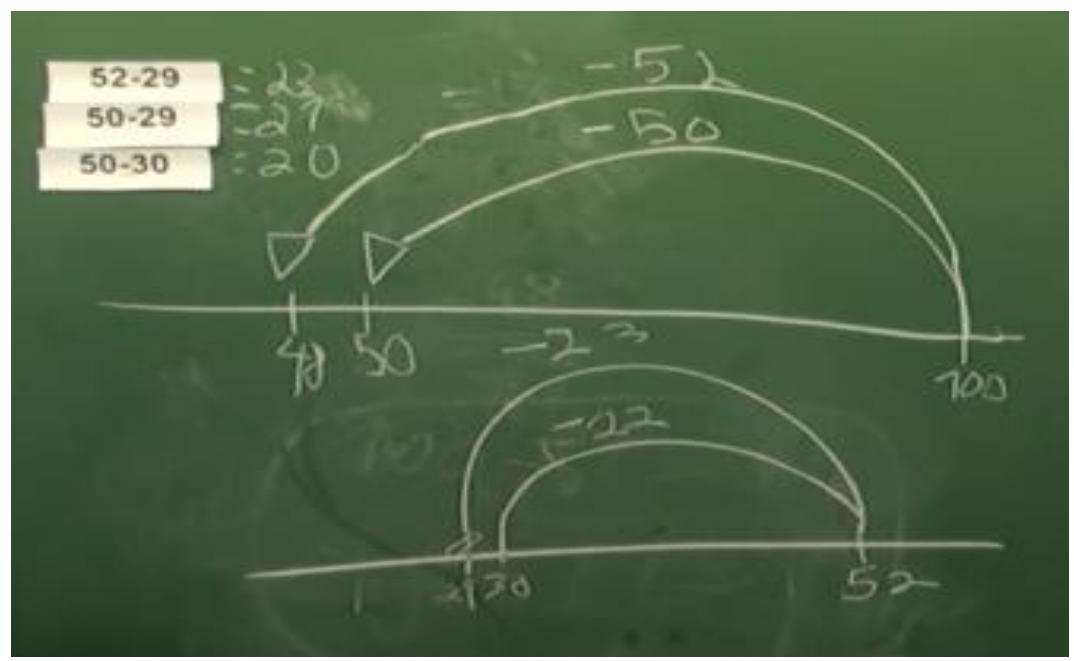

Figure 5. The Work of Santiago and Nadia.

The pair Nadia and Santiago used the empty number line in a different way than the teacher, putting the subtractive on the line instead of being placed above the arrow (the jump). In 52-29, they decided to subtract from 52 other number with the same units, 22, to obtain exact tenths, 30, and then plus 1 (more than 22) to obtain 23 in the jump, insofar as 29 is 1 less than 30 , as observed by Nadia ("29 is before 30"). Therefore, the pair determined the difference, 23 , in the jump, and not on the line. Given this use of the line, the teacher asked the pair why 52-23 helps to calculate 52-29 if there was not that card, but they could not answer. So, the teacher challenged all students to think about it. It was Luís who went to the blackboard and said:

Luís: Because 29 plus this [points to 23 in the number line], equals this [points to 52].

Teacher: [rephrasing Luís to explain the numbers involved]: Because 29 plus 23 is 52. If I know that 52 minus 23 is 29, so 52 minus 29 equals to 23. (Code: Informing Action)

With these new expressions, Luís replicated the reason he had invoked in the previous situation with $100-48=52$ and $100-52=48$. The teacher validated Luís's answer, trying to have students involved in the same reasoning.

Among all the teacher's actions observed and reported here, the supporting/guiding and challenging ones were the most used. In terms of frequencies, the action codes in descending order of use were: 
Supporting/Guiding $=11$, Challenging $=9$, Informing/Suggesting $=5$, and Inviting $=4$.

\section{Discussion}

Relative to the first empirical research question, this teacher used all four coded actions during the whole class discussion. The guiding action was used to focus students' attention on the relations between the expressions represented on the cards, and the challenging action was used mainly to elicit justifications from students. Inviting and informing actions were less used regarding all the teacher's actions. With respect to inviting action, it was used to ask students to present their resolutions and reasoning. The informing action was used mainly to rephrase students' statements to make their meaning explicit, thereby producing clearer mathematical language. Rephrasing was used by the teacher to validate students' responses and to focus their attention on mathematical ideas. The informing action was also used to remind students of operation properties already learned, as happened with the property of invariance ("if we want to keep the result, what I do in the additive, I have to do it in the subtractive"). The way the teacher managed the discussion might correspond to her teaching style of showing a great concern with deepening the arithmetic aspects in the discussion.

Concerning the second empirical research question, we infer that the teacher's actions are closely related to students' flexibility in mental arithmetic, especially the more frequent guiding and challenging actions. Given the limitation of a single lesson segment, the study reported here has insufficient data to draw unequivocal conclusions about the teacher's impact on her students' mental flexibility. The teacher's guiding and challenging actions (Ponte et al., 2013) were relevant in leading the students to further development in establishing numerical relationships (Threlfall, 2009). With these actions, the teacher favored the conceptual understanding of her students. As argued by Gravemeijer and Bruin-Muurling (2019), conceptual understanding plays a fundamental role in developing flexibility in arithmetic.

The guiding action is associated with the teacher's clear awareness of the goal of the task. In this vein, she keeps in mind the concern of maintaining the focus of the whole class discussion on achieving new results through the connections between the several cards' expressions. To lead the students to establish these connections, the teacher guides them, making questions centered on the similarities of number expressions and on known facts (as "How much is 100-50?"). In this way, she hoped that her students would be able to relate the known results with the new ones (Gray \& Tall, 1994) (for instance, "How can this help to make 100 minus 48? Let's think."). The results of this study illustrate the importance of guiding actions for leading the students to relate numbers and operations, thereby contributing to the development of their flexibility in mental calculation. 
This teacher seems to have high expectations towards her students' and uses the challenging action to encourage her students to reason about number relations ("How do you know? [100-52=48]"), asking them to justify what they say ("Why?") and to interpret the relationships established ("What does it mean?"). The teacher is also concerned with maintaining the cognitive demand of the task (Gravemeijer et al., 2016; Stein \& Smith, 2009), not giving the answer and making the students' progress in their thinking.

It appears that the challenging action played a crucial role in students' development of flexibility in arithmetic because it is based on a deeper conceptual understanding as a foundation for a flexible calculation. In contrast to what happens when students show mastery of procedural skills without understanding the underlying mathematics (Brocardo, 2014), the second graders' answers reported here show a flexible use of numbers, grounded in building number relations which are established comprehensively. This type of calculation requires numbers to become objects of thought (Gravenjeijer \& Bruin-Muurling, 2019), and the networks of number relations are promoted substantially by the teacher's challenging questioning. Moreover, this action owes its effectiveness to its conjunction with other actions, namely inviting students to participate, supporting their ideas, guiding them to the intended goal in each moment, and clarifying what has been discussed. So, in the context of the lesson segment, it seems that the teacher's actions were fundamental in generating meaningful arithmetic knowledge (Baroody \& Rosu, 2006; Rathgeb-Schnierer \& Green, 2013, 2019). The teacher's questioning, in particular, appears, on one hand, to increase the students' flexibility in mental calculation, leading them to move forward in establishing relationships between numbers and operations, and on the other hand, to facilitate their communication of those relationships.

This study suggests several areas of future research. For example, we need to understand much better how students work with mental objects and create networks of number relations. We also need more empirical evidence about how teachers' actions may foster the development of mental flexibility, which would ideally come from a longitudinal study.

\section{References}

Anghileri, J. (2001). Intuitive approaches, mental strategies, and standard algorithms. In J. Anghileri (Ed.), Principles and practices in arithmetic teaching (pp. 79-94). Open University Press.

Baroody, A. J., \& Rosu, L. (2004, April). Adaptive expertise with basic addition and subtraction combinations: The number sense view. In A. J. Baroody \& T. Torbeyns (chairs), Developing adaptive expertise in elementary school arithmetic. Symposium conducted at the meeting of the American Educational Research Association, San Francisco, CA. 
Boaler, J. (2003). Studying and capturing the complexity of practice: The case of the dance of agency. In N. Pateman, B. J., Dougherty, \& J. T. Zilliox (Eds.), Proceedings of $27^{\text {th }}$ Conference. of the International Group for the Psychology of Mathematics Education (Vol. 1, pp. 316). Honolulu, USA: PME.

Bogdan, R., \& Biklen, S. K. (1994). Investigação Qualitativa em Educação: Uma introdução à teoria e aos métodos. Porto: Porto Editora.

Brocardo, J. (2014, September). Exploring flexibility in mental calculation in the domain of multiplicative reasoning [Paper presentation]. ECER, Porto, Portugal.

Cengiz, N., Kline, K., \& Grant, T. J. (2011). Extending students' mathematical thinking during whole-group discussions. Journal of Mathematics Teacher Education, 14, 355-374.

Erickson, F. (1986). Qualitative methods in research on teaching. In M. C. Wittrock (Ed.), Handbook of research on teaching (3rd ed., pp. 119161). Macmillan.

Gravemeijer, K., \& Bruin-Muurling, G. (2019). Fostering process-object transitions and a deeper understanding in the domain of number. Quadrante, 28(2), 6-31.

Gravemeijer, K., \& Cobb, P. (2006). Design research from the learning design perspective. In T. Plomp \& N. Nieveen (Eds.), Educational design research (pp. 72-113). Netherlands Institute for Curriculum Development (SLO).

Gravemeijer, K., Bruin-Muurling, G., Kraemer, J. M., \& van Stiphout, I. (2016). Shortcomings of mathematics education reform in The Netherlands: A paradigm case? Mathematical Thinking and Learning, 18(1), 25-44.

Gray, E., \& Tall, D. (1994). Duality, ambiguity and flexibility: A perceptual view of simple arithmetic. Journal for Research in Mathematics Education, 26(2), 115-141.

Hatano, G. (2003). Foreword. In A. J. Baroody \& A. Dowker (Eds.). The development of arithmetic concepts and skills (pp. xi-xiii). Erlbaum.

Heinze, A., Marschick, F., \& Lipowsky, F. (2009). Addition and subtraction of three-digit numbers: Adaptive strategy use and the influence of instruction in German third grade. ZDM Mathematics Education, 41(5), 591-604.

Heirdsfield, A., \& Cooper, T. J. (2004). Factors affecting the process of proficient mental addition and subtraction: Case studies of flexible and inflexible computers. The Journal of Mathematical Behavior, 23(4), 443-463.

Kilpatrick, J., Swafford, J., \& Findell, B. (2001). Adding it up: Helping children learn mathematics. National Academy Press.

National Council of Teachers of Mathematics. (2000). Principles and standards for school mathematics. 
Ponte, J. P., \& Quaresma, M. (2016). Teachers' professional practice conducting mathematical discussions. Educational Studies in Mathematics, 93(1), 51-66.

Ponte, J. P., Mata-Pereira, J., \& Quaresma, M. (2013). Ações do professor na condução de discussões matemáticas. Quadrante, 22(2), 55-81.

Rathgeb-Schnierer, E., \& Green, M. (2013). Flexibility in mental calculation in elementary students from different math classes. In B. Ubuz, Ç. Haser, \& M.A. Mariotti (Eds.), Proceedings of the Eighth Congress of the European Society for Research in Mathematics Education (pp. 353-362). Ankara: Middle East Technical University.

Rathgeb-Schnierer, E., \& Green, M. (2015). Cognitive flexibility and reasoning patterns in American and German elementary students when sorting addition and subtraction problems. In K. Krainer \& N. Vondrová (Eds.), Proceedings of the Ninth Congress of the European Society for Research in Mathematics Education (pp. 339-345). Prague: Charles University in Prague, Faculty of Education and ERME.

Rathgeb-Schnierer, E., \& Green, M. (2019). Developing flexibility in mental calculation. Educação \& Realidade, 44(2). https://doi.org/10.1590/2175-623687078

Rechtsteiner-Merz, C., \& Rathgeb-Schnierer, E. (2015). Flexible mental calculation and "zahlenblickschulung". In K. Krainer \& N. Vondrová (Eds.), Proceedings of the Ninth Congress of the European Society for Research in Mathematics Education (pp. 354-360). Charles University in Prague, Faculty of Education and ERME.

Ruthven, K., Hofmann, R., \& Mercer, N. (2011). A dialogic approach to plenary problem synthesis. In B. Ubuz (Ed.), Proceedings of $35^{\text {th }}$ Conference of the International Group for the Psychology of Mathematics Education (Vol. 4, pp. 81-88). Ankara, Turkey: PME.

Selter, C. (2009). Creativity, flexibility, adaptivity, and strategies use in mathematics. ZDM Mathematics Education, 41, 619-625.

Star, J. R., \& Newton, K. J. (2009). The nature and development of experts' strategy flexibility for solving equations. ZDM Mathematics Education, 41, 557-567.

Stein, M. K., Engle, R. A., Smith, M. S., \& Hughes, E. K. (2008). Orchestrating productive mathematical discussions: Five practices for helping teachers move beyond show and tell. Mathematical Thinking and Learning, 10(4), 313-340.

Stein, M., \& Smith, M. (2009). Tarefas matemáticas como quadro para a reflexão: Da investigação à prática (original article published in 1998). Educação e Matemática, 105, 22-28.

Threlfall, J. (2009). Strategies and flexibility in mental calculation. ZDM Mathematics Education, 41, 541-555. 
Torbeyns, J., De Smedt, B., Ghesquière, P., \& Verschaffel, L. (2009). Jump or compensate? Strategy flexibility in the number domain up to 100. ZDM - The International Journal on Mathematics Education, 41, 581-590.

Verschaffel, L., Luwel, K., Torbeyns, J., \& Dooren, W. V. (2009).

Conceptualizing, investigating, and enhancing adaptive expertise in elementary mathematics education. European Journal of Psychology of Education, 24(3), 335-359.

\section{Authors:}

Lurdes Serrazina

Margarida Rodrigues

Escola Superior de Educação, Instituto Politécnico de Lisboa,

UIDEF, Instituto de Educação, Universidade de Lisboa

Email: lurdess@eselx.ipl.pt

Margarida Rodrigues

Escola Superior de Educação, Instituto Politécnico de Lisboa, UIDEF, Instituto de Educação, Universidade de Lisboa

Email: margaridar@eselx.ipl.pt

Corresponding author: Lurdes Serrazina 